\title{
Traffic Impact Study and Signal Design at Suchitra Junction, Qutubullapur, Rangareddy, Telangana, India
}

\author{
K Venkatesh ${ }^{1}$, Ratod Vinod Kumar $^{2}$ \\ ${ }^{1,2}$ Assistant Professor, Department of Civil Engineering, Malla Reddy Institute of Technology \& Science, Maisammaguda, Dulapally, \\ Ranga Reddy, 500100
}

\begin{abstract}
TIS (Traffic impact study) is generally required to support the transportation aspects of a proposed development that has the potential to generate significant amounts of pedestrians, bicycle trips, transit users and vehicular traffic. Traffic rules and regulations are devised to assure the smooth flowing of motor vehicles in the road. Moreover, traffic rules and regulation are not only for the driver of the vehicles but at the same times these rules are meant for the pedestrians, cyclist, motor-cyclist and other road users. Traffic signal is an aid to control traffic at intersections where other control measures fail. The signals operate by providing right of way to a certain set of movements in a cyclic order. The necessary data should be collected by means of traffic engineering studies. Minimum vehicular volume, interruption of continuous traffic, minimum pedestrian volume, accident experience, combination of above warrants. Combination of warrants when no single warrant is satisfied but indicating two or more warrants of above are satisfied to the extent of 80 percent or more of the stated volume. Traffic control signal shall be installed at Suchitra junction for the following signal warrants meeting. As the average traffic flow for 8 hours on both approaches exceeding 800 vehicles. Interruption of continuous traffic flow on the major street exceeding 1000 vehicles per hour. As 150 or more pedestrians per hour crossing a major street with over 600 vehicles per hour on both approaches.
\end{abstract}

Keywords: Literature review, study area, traffic impact study, methodology, traffic signals

\section{Introduction}

Traffic Impact Study (TIS) is a systematic and scientific study to analyze the impact of the traffic generated by a new development on the surrounding transportation system. A TIS is generally required to support the transportation aspects of a proposed development that has the potential to generate significant amounts of pedestrians, bicycle trips, transit users and vehicular traffic. A well-prepared traffic impact study helps the developer and permitting agency accomplish the following:

- Forecast the traffic impacts created by proposed development based on accepted practices, not perceptions.

- Determine improvements needed to accommodate the proposed development.

- Allocate funds more efficiently.

- Evaluate more number, location, and design of access points.

- Update traffic data.

- Identify needed roadway improvements.

- Provide a basis for determining the developer's responsibility for specific off-site improvements.

\section{Study Area}

Suchitra Junction or Suchitra Center Suchitra cross roads is one of the fastest growing suburbs of Hyderabad, India. It has become a hub on Bowenpally-Medchal Road. The western road leads to Chintal, Shahpur, Jeedimetla, IDPL. The eastern road leads to Alwal via Loyola College. Suchitra is witnessing traffic issues during rush hours.
Traffic impact studies help communities to

- Forecast additional traffic associated with new development, based on practices.

- Determine the improvements that are necessary to accommodate the new development.

- Assist communities in land use decision making.

- Assist in allocating scarce resources to areas which need improvements.

- Identify potential problems with the proposed development which may influence the developer's decision to pursue it.

- Allow the community to assess the impacts that a proposed development may have.

- Help to ensure safe and reasonable traffic conditions on streets after development is complete.

- Reduce the negative impacts created by developments by helping to ensure that the transportation network can accommodate the development.

- Provide decision to community decision makers and developers of expected impacts.

- Protect the substantial community investment in the street system.

- Traffic impact studies should be used as one piece of several kinds of information to judge the suitability of development from a transportation stand point.

Satellite View of Suchitra Junction 

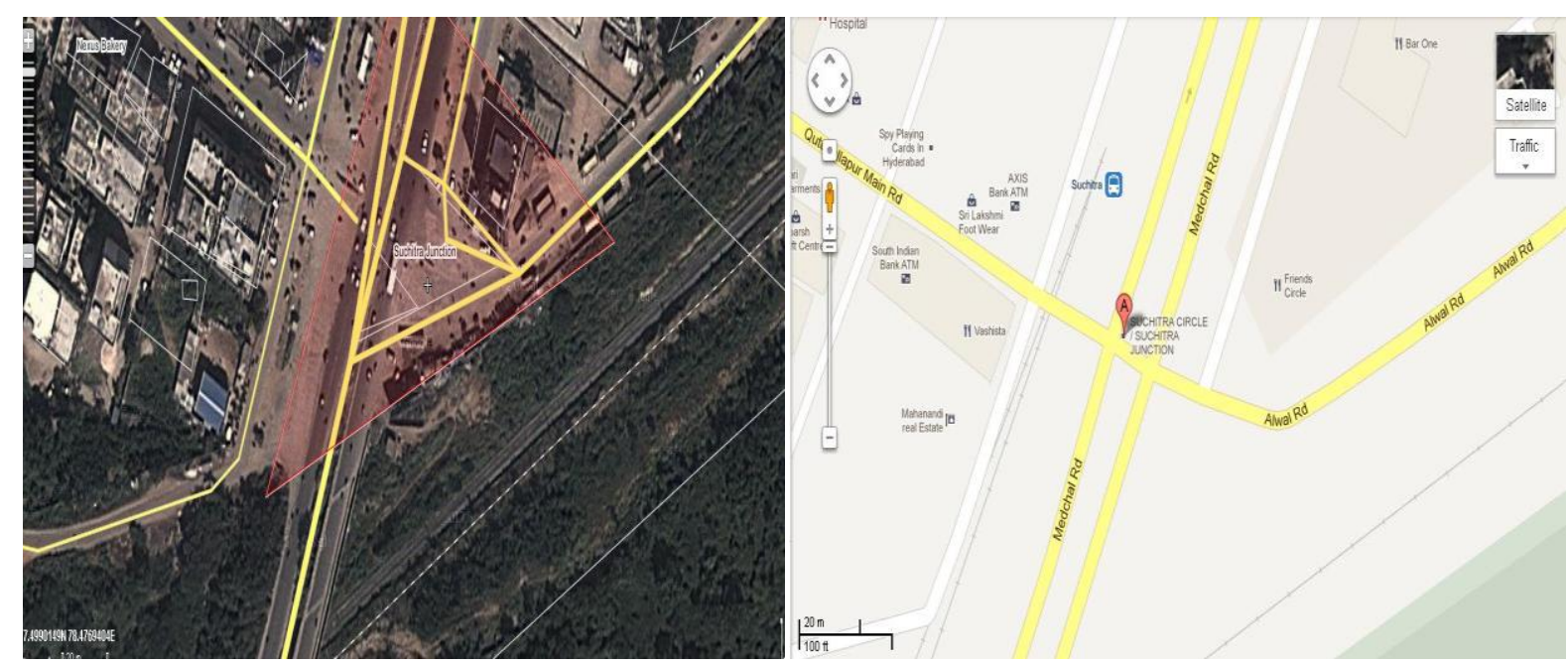

\begin{tabular}{|c|c|}
\hline Land Use & Typical Peak Hours \\
\hline Residential & 7:00-9:00 am weekday and 4:00-6:00 \\
& pm weekday \\
\hline Regional shopping centre & 2:30-3:30 pm weekends \\
& 5:00-6:00 pm weekdays \\
\hline Office & 7:00-9:00 am weekday 4:00-6:00 pm \\
& weekday \\
\hline
\end{tabular}

\section{Literature Review}

L.R Kadiyali ${ }^{2}$ Said that a number of definitions and notations need to be understood in signal design. They are discussed below:

1) Cycle: A signal cycle is one complete rotation through all of the indications provided.

2) Cycle length: Cycle length is the time in seconds that it takes a signal to complete one full cycle of indications. It indicates the time interval between the starting of green for one approach till the next time the green starts. It is denoted by $\mathrm{C}$.

3) Interval: Thus it indicates the change from one stage to another.

4) Green interval: It is the green indication for a particular movement or set of movements and is denoted by "Gi". This is the actual duration the green light of a traffic signal is turned on.

5) Red interval: It is the red indication for a particular movement denoted by "Ri".

6) Phase: A phase is the green interval plus the change and clearance intervals that follow it. Thus, during green interval, non conflicting movements are assigned into each phase. It allows a set of movements to flow and safely halt the flow before the phase of another set of movements start.

7) Lost time: It indicates the time during which the intersection is not effectively utilized for any movement.

\section{Slater $\mathbf{R} . \mathbf{J}^{\mathbf{4}}$ said about traffic signal signs}

(1)Circular green alone: Vehicular traffic facing a green signal may proceed straight through or turn right or left unless a sign or marking at such place prohibits either such turn or straight through movement, except that such traffic shall yield the right of-way to pedestrians and vehicles lawfully within a crosswalk or the intersection at the time such signal was exhibited; pedestrians facing the green signal, except when directed by separate pedestrian-control signals, may proceed across the highway within any marked or unmarked crosswalk.

(2) Yellow: Vehicular traffic facing a steady yellow signal is thereby warned that the related green movement is being terminated or that a red indication will be exhibited immediately thereafter, when vehicular traffic shall stop before entering the intersection unless so close to the intersection that a stop cannot be made in safety ; pedestrians facing a steady yellow signal, except when directed by separate pedestrian-control signals, are thereby advised that there is insufficient time to cross the roadway before a red indication is shown and no pedestrian shall then start to cross the roadway.

(3) Red alone: Vehicular traffic facing a steady red signal alone shall stop before entering the crosswalk on the near side of the intersection or, if none, then before entering the intersection and remain standing until the next indication; provided, on or after July 1, 1979, vehicular traffic traveling in the travel lane nearest the right hand curb or other defined edge of the roadway, unless a sign has been erected in the appropriate place prohibiting this movement, may cautiously enter the intersection to make a right turn onto a two-way street or onto another one-way street on which all the traffic is moving to such vehicle's right after such vehicle has stopped as required in this subdivision and yielded the rightof-way to pedestrians lawfully within an adjacent crosswalk and to other traffic lawfully using the intersection..

(4) Green arrow: Vehicular traffic facing a green arrow signal, shown alone or in combination with another indication, may cautiously enter the intersection only to make the movement indicated by such arrow, or such other movement as is permitted by other indications shown at the same time, but such vehicular traffic shall yield the right-ofway to pedestrians lawfully within a crosswalk and to other traffic lawfully within the intersection. 


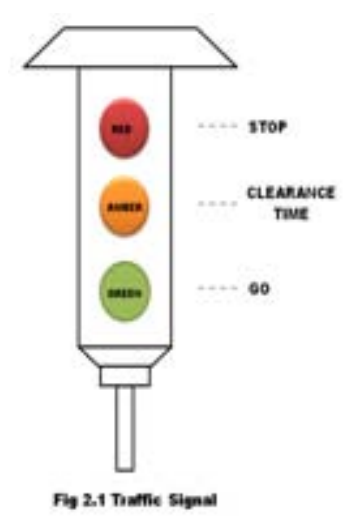

Rao G. $\mathbf{V}^{\mathbf{5}}$ said that traffic signals control vehicle and pedestrian traffic by assigning priorities to various traffic movements to influence traffic flow. Properly designed, located and maintained traffic signals have one or more of these advantages:

- Provide for orderly movement of traffic;

- Increase traffic-handling capacity of an intersection;

- Reduce frequency and severity of certain types of crashes, especially right-angle collisions;

\section{Methodology}

To approximate design procedures and one rational approach (Webster's method) for the design of traffic signal cycles are given below for fixed time traffic signals at cross roads. In addition the signal design method as per the guidelines of the IRC is also given. For the purpose of simplicity, two phase traffic signals with no turning movements are illustrated here. The methods may be suitably extended for multi phase operation.

Trial Cycle Method: The 15 minute-traffic counts $\mathrm{n}_{1}$ and $\mathrm{n}_{2}$ on roads 1 and 2 are noted during the design peak hour flow. Some suitable trial cycle $\mathrm{C}_{1}$ second is assumed and the number of the assumed cycles in the 15 minutes or $10 \times 60$ seconds period is found to be $(15 \times 60) / C_{1}$, i.e. $\left(900 / C_{1}\right)$. Assuming average time headway 2.5 seconds, the green periods $G_{1}$ and $G_{2}$ of roads 1 and 2 are calculated to clear the traffic during the trial cycle.

$$
\mathrm{G}_{1}=2.5 \mathrm{n}_{1} \mathrm{C}_{1} / 900 \text { and } \mathrm{G}_{2}=2.5 \mathrm{n}_{2} \mathrm{C}_{2} / 900
$$

The amber periods $A_{1}$ and $A_{2}$ are either calculated or assumed suitably ( 3 to 4 seconds) and the cycle length $\mathrm{C}_{1}$ ' is calculated, equal to $\left(G_{1}+G_{2}+A_{1}+A_{2}\right)$ seconds. If the calculated cycle length $\mathrm{C}_{1}$ ' works out to be approximately equal to the assumed cycle length $\mathrm{C}_{1}$, the cycle length is accepted as the design cycle. Otherwise the trial cycles are repeated till the trial cycle length works out approximately equal to the calculated value.

Webster's Method: The optimum signal cycle is given by: $\mathrm{C}_{0}=1.5 \mathrm{~L}+5 / 1-\mathrm{Y}$

Where $\mathrm{L}=$ total lost time per cycle, seconds $=2 \mathrm{n}+\mathrm{R}$ ( $\mathrm{n}$ is the number of phase and $\mathrm{R}$ is all red-time)

$$
\mathrm{Y}=\mathrm{y}_{1}+\mathrm{y}_{2}
$$

Then, $\mathrm{G}_{1}=\mathrm{y}_{1} / \mathrm{Y}\left(\mathrm{C}_{0}-\mathrm{L}\right)$ and $\mathrm{G}_{2}=\mathrm{y}_{2} / \mathrm{Y}\left(\mathrm{C}_{0}-\mathrm{L}\right)$

Similar procedure is followed when there is more number of signal phases.

\section{Analysis and Discussions of Traffic Impact Study}

For the traffic impact study, a four legged intersection is chosen at Suchitra in Hyderabad and conducted a traffic volume count. Here the observation shows the capacity of dual lane carriageway with one direction exceeds by volume travels at the junction. To measure the traffic volume counts manual method of count was adopted.

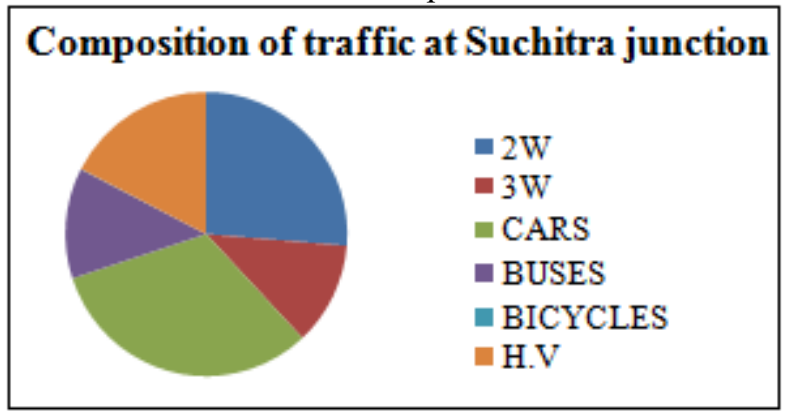

Mode of distribution

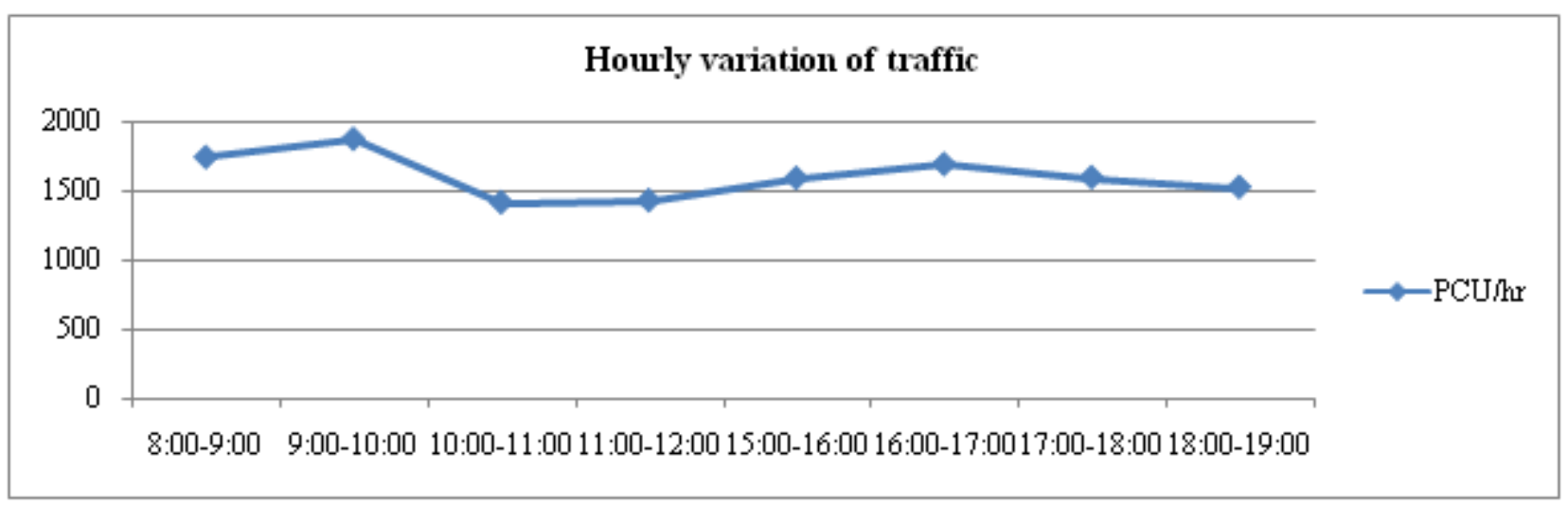

Hourly peak traffic (Time versus Hourly traffic)

\section{Results}

To install signals at an intersection at least one warrant as mentioned in the earlier chapters should be satisfied. For the present study the design hourly volume is more than the motor vehicles per hour. So there is a need to establish traffic signal at the Suchitra junction Design traffic volume on Leg1 $=2044 \mathrm{PCU} / \mathrm{hr}$ Design traffic volume on Leg2 $=1062 \mathrm{PCU} / \mathrm{hr}$ Design traffic volume on Leg3 $=787 \mathrm{PCU} / \mathrm{hr}$

\section{Volume 5 Issue 1, January 2016




\section{International Journal of Science and Research (IJSR) \\ ISSN (Online): 2319-7064 \\ Index Copernicus Value (2013): 6.14 | Impact Factor (2014): 5.611}

Design traffic volume on Leg4=2022 PCU/hr

Approach volume per lane on leg1:n1 $=2044 / 2=1022 \mathrm{pcu} / \mathrm{hr}$ Approach volume per lane on leg2:n2 $=1062 / 2=531 \mathrm{pcu} / \mathrm{hr}$ Approach volume per lane on leg3:n3=787/2=393pcu/hr Approach volume per lane on leg4:n4 $=2022 / 2=1011 \mathrm{pcu} / \mathrm{hr}$

1. Pedestrian green time for $\operatorname{Leg} 1=18 / 1.2+7.0=22.0 \mathrm{sec}$ Pedestrian green time for Leg2 $=13.8 / 1.2+7.0=18.0 \mathrm{sec}$ Pedestrian green time for Leg3 $=14 / 1.2+7.0=19.0 \mathrm{sec}$ Pedestrian green time for Leg4 $=20.5 / 1.2+7.0=24.0 \mathrm{sec}$

2. Green time for vehicles on $\operatorname{Leg} 2, \mathrm{G}_{2}=25.0 \mathrm{sec}$

3. Green time for Leg1, $\mathrm{G}_{1}=25.0 *(1022 / 531)=48.0 \mathrm{sec}$ Green time for Leg3, $\mathrm{G}_{3}=25.0 *(704 / 794)=10.0 \mathrm{sec}$ Green time for Leg4, G4 $=25.0 *(1011 / 1022)=25.0 \mathrm{sec}$

4. Adding 3.0secs each towards clearance amber and 4.0 sec.

5. Inter-Green period for each phase,

6. Total cycle time required $=(3+48+4)+(3+25+4)+(3+10+4)+(3+25+4)=136.0 \mathrm{sec}$

7. The extra $3.5 \mathrm{secs}$ per cycle may be apportioned to the green times of Leg1,Leg2,Leg3,Leg4 as 1.0,1.0,1.0and $1.0 \mathrm{sec}$ and so

$\mathrm{G}_{1}=48+1=49.00 \mathrm{sec}$

$\mathrm{G}_{2}=25.00+1.00=26.00 \mathrm{sec}$

$\mathrm{G}_{3}=10.00+1.00=11.00 \mathrm{sec}$

$\mathrm{G}_{4}=25.00+1.00=26.00 \mathrm{sec}$

8. Vehicles arrivals per lane cycle on Leg $1=1022 / 136=8.0$ PCU

Minimum green time for clearing vehicles on Leg1 $=6+$ $(8.0-1.0) * 2=20.00 \mathrm{sec}$

Vehicles arrivals per lane cycle on Leg $2=531 / 136=4.0$

PCU

Minimum green time for clearing vehicles on Leg2 $=6+$ $(4.0-1.0) * 2=12.00 \mathrm{sec}$

Vehicles arrivals per lane cycle on Leg $3=393 / 136=3.0$

PCU

Minimum green time for clearing vehicles on Leg3 $=6+$ $(3.0-1.0) * 2=10.00 \mathrm{sec}$

Vehicles arrivals per lane cycle on Leg $4=1011 / 136=7.4$ PCU
Minimum green time for clearing vehicles on Leg4 $=6+$ $(7.4-1) * 2=19.00 \mathrm{sec}$

As the green time provided for the four legs by pedestrian crossing criteria in (iii) above are higher than these values, the above design values are all right.

9. Lost time per cycle $\mathrm{L}=\mathrm{n}(\mathrm{I}-\mathrm{a})+\mathrm{n} * 1=4(4-3)+4 * 2=12.0 \mathrm{sec}$ Where, Amber time, $\mathrm{a}=3 \mathrm{sec}$.

Last time due to starting delays, $1=2$ sec.per phase No. of phases, $n=4$

Inter green period, $\mathrm{I}=4.0 \mathrm{sec}$

Saturation flow for Leg1 $=525 * 9.0=4725 \mathrm{PCU} / \mathrm{hr}$

Saturation flow for Leg2 $=525 * 6.9=3622 \mathrm{PCU} / \mathrm{hr}$

Saturation flow for Leg3 $=525 * 7.0=3675 \mathrm{PCU} / \mathrm{hr}$

Saturation flow for Leg $4=525 * 10.5=5512.5 \mathrm{PCU} / \mathrm{hr}$

Normal flow on Leg $1=\mathrm{y}_{1}=1022 / 4725=0.21$

Normal flow on Leg $2=\mathrm{y}_{2}=531 / 3622=0.14$

Normal flow on Leg $3=\mathrm{y}_{3}=393 / 3675=0.10$

Normal flow on Leg4 $=\mathrm{y}_{4}=1011 / 5512.5=0.18$

Total Normal flow $\mathrm{Y}=\mathrm{y}_{1}+\mathrm{y}_{2}+\mathrm{y}_{3}+\mathrm{y}_{4}$

$=0.33+0.21+0.23=0.65$

Optimum cycle time $\left(\mathrm{C}_{\mathrm{O}}\right)=1.5 \mathrm{~L}+5 / 1-\mathrm{Y}$

$=1.5 * 12+5 / 1-0.65=66.00 \mathrm{sec}$

Therefore the cycle time of $136 \mathrm{sec}$

The effective green time $=136-12=124 \mathrm{sec}$.

The effective green time for phase $1 ; \mathrm{G}_{1}=\mathrm{y}_{1} / \mathrm{Y}^{*}(\mathrm{EGT})$

$=(0.21 / 0.66) * 124.0=39.45 \mathrm{sec}$

Actual green time $=\mathrm{G}_{1}+1-\mathrm{a}=39.45+2-3=38.45 \sim 38 \mathrm{sec}$

The effective green time for phase $2 ; \mathrm{G}_{2}=\mathrm{y}_{2} / \mathrm{Y} *(\mathrm{EGT})$ $=(0.14 / 0.65) * 124.0=26.7 \mathrm{sec}$

Actual green time $=\mathrm{G}_{2}+1-\mathrm{a}=26.7+2-3=25.7 \sim 26 \mathrm{sec}$

The effective green time for phase $3 ; \mathrm{G}_{3}=\mathrm{y}_{3} / \mathrm{Y} *(\mathrm{EGT})=$ $(0.10 / 0.65)^{*} 124.0=19.07 \mathrm{sec}$

Actual green time $=\mathrm{G}_{3}+\mathrm{l}-\mathrm{a}=19.07+2-3=18.07 \sim 18 \mathrm{sec}$

The effective green time for phase $4 ; \mathrm{G}_{4}=\mathrm{y}_{4} / \mathrm{Y} *(\mathrm{EGT})=$ $(0.18 / 0.65)^{*} 124.0=34.3 \mathrm{sec}$

Actual green time $=\mathrm{G}_{4}+\mathrm{l}-\mathrm{a}=34.3+2-3=33.3 \sim 33.0$

The total optimum cycle time required is $136.00 \mathrm{secs}$.

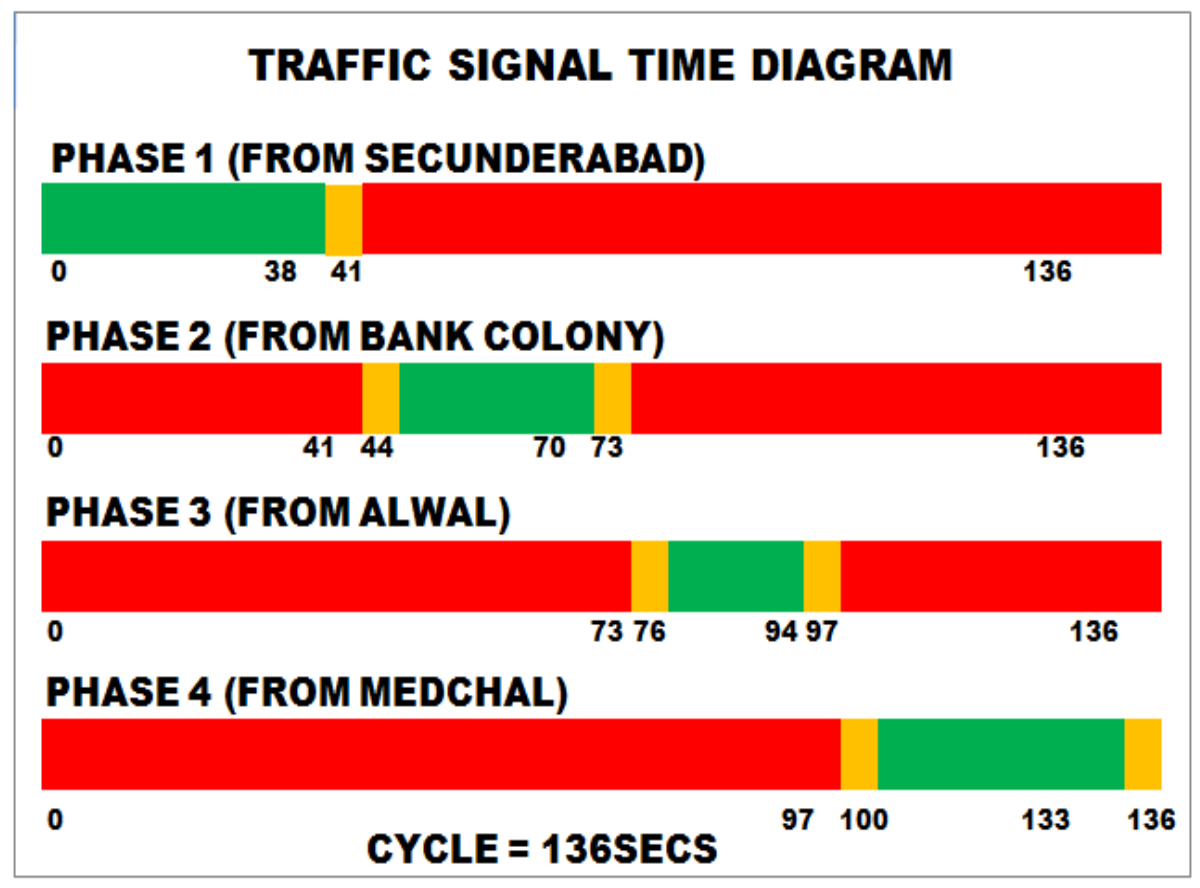




\section{International Journal of Science and Research (IJSR) \\ ISSN (Online): 2319-7064}

Index Copernicus Value (2013): 6.14 | Impact Factor (2014): 5.611

The layout of the junction with total volume and design hourly volume is pictorially represented. The design calculations are presented in this chapter. The signal timings are shown in the form of Time Diagrams.

\section{Conclusions}

Traffic control signal shall be installed at Suchitra junction for the following signal warrants meeting.

- As the average traffic flow for 8hours on both approaches exceeding 800 vehicles.

- Interruption of continuous traffic flow on the major street exceeding 1000 vehicles per hour.

- As 150 or more pedestrians per hour crossing a major street with over 600 vehicles per hour on both approaches.

The following information is concluded from our design.

- Total cycle time required in seconds $=136.00$

- Optimum cycle time in seconds $=66.00$

- Actual green time for phase $1=38.00$

- Actual green time for phase $2=26.00$

- Actual green time for phase $3=18.00$

- Actual green time for phase $4=33.00$

\section{References}

[1] Khanna S.K \& Justo C.E.G., "Highway Engineering" New Chand and Bros. Roorkee

[2] Kadiyali L.R., "Traffic Engineering and Transport Planning" Khanna Publishers, New Delhi.

[3] Slater R.J., "Highway Traffic Analysis and Design" Macmillan Series.

[4] Rao G.V., "Principles of Transportation \& Highway Engineering".

[5] Punmia B.C., "Surveying (Voll)" Laxmi Publishers. 